\title{
COGNITIVE AND NON-COGNITIVE FACTORS RELATED TO STUDENTS' STATISTICS ACHIEVEMENT
}

\author{
FRANCESCA CHIESI \\ University of Florence, Italy \\ f.chiesi@tin.it \\ CATERINA PRIMI \\ University of Florence, Italy \\ cprimi@texnet.it
}

\begin{abstract}
The aim of this study was to investigate students' achievement in introductory statistics courses taking into account the relationships between cognitive and noncognitive factors. It was hypothesised that achievement was related to background in mathematics (a cognitive variable), as well as to attitudes toward statistics and anxiety (non-cognitive variables). Students were presented with measures assessing their attitudes, mathematical competence, and anxiety toward courses and examinations at the beginning and at the end of their statistics course. Achievement was assessed by tasks assigned during the course, as well as by students' final grades and the number of exam failures. The results reveal the relationships between cognitive and non-cognitive factors, their changes during the course, and how both interact in predicting achievement.
\end{abstract}

Keywords: Statistics education research; Statistics attitudes; Statistics anxiety; Mathematical competence; Structural equation modeling

\section{INTRODUCTION}

Students pursuing a degree are usually requested to enrol in introductory statistics courses at the beginning of their degree program. In some cases, students only have access to the next courses of their degree program once they have passed an introductory statistics examination, and their final dissertations often require the use of statistics. Unfortunately, many students find it difficult to grasp statistical concepts, thus, they have problems with dealing with this discipline, and they attain low levels of performance. Despite their efforts, instructors of introductory statistics courses that are aimed at preparing students to understand, handle, and make use of research data in their field of study, often fail to achieve this. As a result they experience frustration in doing their work.

These difficulties have been documented in different educational contexts (Carmona, 2004a; Gal, Ginsburg, \& Schau, 1997; Onwuegbuzie \& Seaman, 1995; Schutz, Drogosz, White, \& Distefano, 1998; Tremblay, Gardner, \& Heipel, 2000; Wisenbaker, Scott, \& Nasser, 2000). This seems to be especially true for students attending graduate programs that are traditionally qualitative, such as degrees in Psychology (Lalonde \& Gardner, 1993; Tremblay et al., 2000) or Educational and Social Sciences (Nasser, 2004; Onwuegbuzie, 2003; Schutz et al., 1998; Wisenbaker et al., 2000), where introductory

Statistics Education Research Journal, 9(1), 6-26, http://www.stat.auckland.ac.nz/serj

(C) International Association for Statistical Education (IASE/ISI), May, 2010 
statistics and/or quantitative-based research methodology courses are required. Many students consider these courses a burden because they are not self-confident about their skills in quantitative disciplines and, consequently, they experience stress and anxiety. Moreover, many students believe that these courses are of no use and not fundamental to their degree programs.

The relationships among the above mentioned factors and their effect on performance have been studied in order to better understand the underlying mechanisms of statistics achievement (Bandalos, Finney, \& Geske, 2003; Budé et al., 2007; Nasser, 2004; Perney \& Ravid, 1990; Schutz et al., 1998; Sorge \& Schau, 2002; Tremblay et al., 2000), to predict performance (Fitzgerald, Jurs, Hudson, 1996; Lalonde \& Gardner, 1993; Onwuegbuzie, 2003; Tempelaar, Van Der Loeff, \& Gijselaers, 2007) and to enhance success (Elmore \& Lewis, 1991; Harlow, Burkholder, \& Morrow, 2002; Onwuegbuzie \& Seaman, 1995). Most of these studies presented models in which the causal paths between variables related to achievement are explored using structural equation modelling techniques.

Tremblay and colleagues (2000) started from Lalonde and Gardner's (1993) study in which statistics learning was conceptualized as similar to second language learning. Lalonde and Gardner proposed a model in which achievement was related to individuals' mathematical aptitude, statistics anxiety and attitudes, as well as motivation to learn statistics and effort. More specifically, it was hypothesized that aptitude would be a direct positive cause of achievement and a negative cause of anxiety, which in turn would be a cause of both achievement and motivation, a factor related to effort. Analyses revealed that all the hypothesized paths were significant except the direct path between achievement and anxiety: Performance in statistics was directly predicted by mathematics aptitude and motivation, whereas attitudes and anxiety influenced indirectly achievement through motivation. Introducing some indicators for academic achievement, Tremblay et al. replicated Lalonde and Gardner's results and, in contrast to the previous study, they found that anxiety also affected achievement directly. Furthermore, attitudes had an effect on anxiety: Unfavourable attitudes toward the course resulted in high levels of anxiety which, in turn, reduced performance.

In these models, attitude toward statistics was measured once, in the first part (Lalonde \& Gardner, 1993) or in the middle of the course (Tremblay et al., 2000). Wisenbaker and colleagues (2000) hypothesised that statistics classes had an effect on attitudes, so they assessed attitudes both at the beginning and at the end of the course. Results revealed that attitudes at the end, but not at the beginning, were good predictors of achievement.

This result was taken into account by Sorge and Schau (2002), who measured attitudes only at the end of the course. They proposed a model based on Eccles and colleagues' (1983) application of the Expectancy-Value models of behaviour to mathematics achievement. They posited that statistics achievement was influenced by attitudes toward statistics, which is considered as a four-dimensional construct (Dauphinee, Schau, \& Stevens, 1997; Schau, Stevens, Dauphinee, \& Del Vecchio, 1995). More specifically, statistics achievement was related to the perception of outcomes from prior learning experiences, and to the four endogenous attitudes' latent constructs: Difficulty (which represented attitudes towards the difficulty of the domain of statistics); Cognitive Competence (which corresponded to students' perception regarding whether they possessed the knowledge and ability needed to learn statistics); Affect (which represented students' positive and negative feelings about statistics); and Value (which was the students' perception of the value of statistics). All of these latent variables were 
allowed to impact on achievement both directly and indirectly through all the possible downstream paths.

The model was tested with a sample of engineering students and the results showed a strong relationship between previous success and achievement in statistics. Those who reported better results, achieved more highly in an introductory statistics course. Attitudes were also an important predictor of statistics achievement, but the impact was lower. Complex relationships were found among the four dimensions of attitudes. Only Affect had a direct impact on achievement; no relationship was found between Value allocated to statistics and achievement, confirming previous results (Wise, 1985; Wisenbaker et al., 2000). Cognitive Competence and Difficulty had an indirect impact through feelings about the discipline. Value and Difficulty were directly negatively related (the easier the discipline, the less the attributed value), but those who believed that statistics was accessible reported that they were more confident in their ability to learn statistics, and, thus, evaluated it more positively. Furthermore, higher perceived competence increased the liking of statistics, which improved achievement.

Onwuegbuzie (2003) proposed a model of statistics achievement amongst graduate Psychology and Educational disciplines, called the Anxiety-Expectation Mediation (AEM) model. The AEM model was first proposed for foreign language achievement by Onwuegbuzie, Bailey, and Daley (2002). As it could be argued that learning statistics is akin to learning a foreign language (Lalonde \& Gardner, 1993), the same model was put forward for statistics achievement. It was hypothesized that high anxiety was associated with poor computational self-concept and low expectation of achievement, and both acted as factors to mediate the relationship between performance and other cognitive, personality, and demographics variables (such as study habits or college background). Concerning assessment time, it has to be stressed that all the predictor variables included in the model were measured in the first days of classes. Results confirmed the link between anxiety and performance (Onwuegbuzie, 1998, 2000; Onwuegbuzie \& Seaman, 1995; Tremblay et al., 2000; Zeidner, 1991). The relationship between performance and expectation of own performance is considered as an important manifestation of selfefficacy (Bandalos et al., 2003; Onwuegbuzie et al., 2002), so anxiety and expectation can be considered the best predictors of achievement in statistics courses (Fitzgerald et al., 1996).

Nasser (2004) examined the extent to which anxiety and attitudes toward mathematics and statistics, motivation, and mathematical aptitude explained the achievement of Arabic-speaking pre-service teachers enrolled in an introductory statistics course. They measured all factors considered to be related to achievement during the course before the midterm examination. Consistent with previous studies (Lalonde \& Gardner, 1993; Sorge \& Schau, 2002; Tremblay et al., 2000; Wisenbaker et al., 2000), they reported a high positive effect of mathematical aptitude and a lower, but significant, positive effect of attitudes on performance (Sorge \& Schau, 2002; Wisenbaker et al., 2000). Mathematics anxiety was found to be directly linked to attitudes: A strong negative effect was reported indicating that high level of mathematics anxiety is related to low level of positive attitudes toward statistics. On the other hand, the hypothesized path between statistics anxiety and achievement was not observed: Anxiety appeared not to be causally related to performance, which was consistent with Lalonde \& Gardner (1993) but was in contrast with Onwuegbuzie (2003) and Tremblay et al. (2000). Motivation did not have a direct effect on achievement but it had a positive, albeit modest, effect on attitudes as reported previously by Auzmendi (1991). More recently, Budé et al. (2007) focused on motivational constructs (partially overlapping with some dimensions of 
attitude towards statistics) finding that affect towards the discipline influenced performance strongly.

Finally, Tempelaar et al. (2007) investigated the relationships among students' prior reasoning abilities (Garfield, 2003), their attitude toward statistics - considered as a multidimensional construct following Schau et al. (1995) - and achievement. Using a large sample of economics students enrolled in an introductory statistics course, they developed a structural equation model in which Cognitive Competence and Difficulty affected course performance (similarly to Sorge \& Schau, 2002), whereas statistical reasoning had little impact on the course performance factors. Similarly, the relationship between statistical reasoning and attitude was weak.

This literature review suggests that the relationships between cognitive and noncognitive factors related to statistics achievement are quite complex. Starting from these premises, the present study is aimed at better ascertaining the impact of both cognitive and non-cognitive factors on course performance.

First, taking into account the major findings of the above mentioned studies, the present research reports on an attempt to model achievement in statistics inside a structural equation model (SEM) approach. Previous mathematical achievement was considered as the exogenous latent variable in the model that was supposed to influence directly both mathematical competence and attitudes toward statistics as shown at the beginning of the course. We posited that these latent variables affected anxiety experienced during the course before the final examination and the attitudes at the end of the course. All these variables were hypothesised to be directly or indirectly related to the final performance in statistics, the outcome variable in the model.

Second, in order to better understand the interplay between cognitive and noncognitive factors, we explored the changes in attitudes toward statistics during the course taking into account students' initial mathematics knowledge. Students enter introductory statistics courses with background competence and views about the subject, as well as about their own ability relating to the subject. The course has an impact on these factors, but the magnitude of this impact depends on background characteristics. The literature regarding the changes in affective components attested that they are quite stable (Gal et al., 1997) but they can also fluctuate depending on individual differences and students' experiences during the classes. More specifically, we aimed to ascertain whether the interaction with the contents and the requirements of the discipline would modify attitudes toward statistics - this is why attitudes were measured twice - and whether this change was mediated by initial mathematical competence. We expected less improvement in attitude for students with lower mathematical competence than for students with higher mathematical competence.

\section{METHODS}

\subsection{PARTICIPANTS}

Data were collected from 487 psychology students enrolled in an undergraduate introductory statistics course at the University of Florence in Italy. The course was scheduled to take place over 10 weeks, at 6 hours per week (for a total amount of 60 hours). It covered the usual introductory topics of descriptive and inferential statistics, and their application in psychological research. During each class some theoretical issues were introduced followed by practical examples and exercises. Students were requested to solve exercises by paper-and-pencil procedure, and no computer package was used. 
They were encouraged to work in small groups in the class and at home. Moreover, two hours per week counselling was offered in order to meet and help individual students.

Participants' age ranged from 19 to 54 with a mean age of 21.4 years $(S D=4.15)$, and most of the participants were women (82.6\%). This percentage reflects the gender distribution of the population of psychology students in Italy. All students participated on a voluntary basis after they were given information about the general aim of the investigation (i.e., collecting information in order to improve students' statistics achievement).

\subsection{MEASURES}

Survey of Attitudes Toward Statistics (SATS) From a number of survey instruments, the SATS (Schau et al., 1995) was chosen for several reasons. First, its adaptability to worldwide introductory statistics courses as attested by Wisenbaker et al. (2000) and Nasser (2004) who used an Arabic version of SATS to assess attitudes toward statistics in Arabic-speaking students enrolled in an introductory statistics course in Israel, by Carmona (2004b) who administered the SATS to introductory statistics course college students attending two Spanish universities, and by Tempelaar et al. (2007) who used the SATS with a Dutch sample. Second, it provides a multidimensional measure of attitude that includes the perception of statistics in itself and as part of the degree program, as well as affective and cognitive components. Third, its psychometric properties have been documented (Cashin \& Elmore, 2005; Dauphinee et al., 1997; Schau et al., 1995; Hilton, Schau, \& Olsen, 2004), it is short and easy to administer, it was developed for students enrolled in introductory statistics courses, and it provides versions to use at the beginning (pre-SATS) and at the end (post-SATS) of the course.

The Italian version of SATS was validated through confirmatory factor analysis, and good indices for both reliability and validity were obtained (Chiesi \& Primi, 2009). Measures of validity were also assessed testing the structure invariance across Spanish and Italian samples (Carmona, Primi, \& Chiesi, 2008).

The SATS contains 28 Likert-type items using a 7-point scale ranging from strongly disagree to strongly agree. The SATS assesses four Attitudes components: Affect (6 items) measures positive and negative feelings concerning statistics (e.g. "I will feel insecure when I have to do statistics problems" or "I will like statistics"); Cognitive Competence (6 items) measures students' attitudes about their intellectual knowledge and skills when applied to statistics (e.g. "I can learn statistics" or "I will make a lot of math errors in statistics"); Value (9 items) measures attitudes about the usefulness, relevance, and worth of statistics in personal and professional life (e.g. "Statistics is worthless" or "Statistical skills will make me more employable"); Difficulty (7 items) measures students' attitudes about the difficulty of statistics as a subject (e.g. "Statistics formulas are easy to understand" or "Statistics is a complicated subject").

For both the pre- and post- versions the SATS responses to negatively scored items were reversed, and then a score was obtained for each subscale, Affect (range 6-42), Cognitive Competence (range 6-42), Value (range 9-63), Difficulty (range 7-49), with higher ratings always representing more positive attitudes.

Prerequisiti di Matematica per la Psicometria (PMP) Previous research on statistics achievement measured students' mathematics background referring to high school achievement (Nasser, 2004; Onwuegbuzie, 2003; Sorge \& Schau, 2002) or to mathematics knowledge that was generally assessed by tests developed for instructional use or for the purpose of the research (Harlow et al., 2002; Lalonde \& Gardner, 1993; 
Schutz et al., 1998). In order to develop a scale to measure accurately the mathematics ability needed by psychology students enrolling in introductory statistics courses, the PMP scale (Galli, Chiesi, \& Primi, 2008) was constructed applying the Rasch model, and its reliability and validity were tested (Galli et al., 2008; Ciancaleoni, Galli, Chiesi, \& Primi, 2008). The contents were defined on the basis of the basic mathematics abilities requested to solve descriptive and inferential statistics problems. Six domains were identified: Operations, Fractions, Set theory (inclusion-exclusion, and intersection concepts), first order Equations, Relations (less than, greater than, equal to relations among numbers that range from 0 to 1 , and numbers expressed in absolute values), and Probability (base-rates, independence notion, disjunction and conjunction rules). Fractions and Operations are employed both in descriptive and inferential statistics tasks (e.g., to compute the standard deviation, as well as the $t$ or $z$ values). Equations are required, for instance, in the standardization procedure and in regression analysis. Establishing Relations between elements is necessary to test hypotheses (i.e., to compare the computed and the critical values to decide whether the null hypothesis has to be maintained or rejected). Set theory principles help to understand probability rules. Probability issues are the prerequisite of hypothesis testing.

The PMP scale is a 30-problem test. Each problem presents a multiple choice question (one correct out of four alternatives) equally distributed in the above mentioned six areas. A single composite, based on the sum of correct answers, was calculated (range 0 -30). In the final part, information about prior achievement was collected based on student self-reports of high school final mathematics grades (range 0-10) and learning debts. (In Italy, high school debts are allocated to students who have insufficient grades due to the lack of achievement at the end of the school year, and they have to pass a test before the beginning of the following year.)

Statistical Anxiety Rating Scale (STARS) Although statistics anxiety has sometimes been measured by scales created to assess academic anxiety or mathematics anxiety, several specific instruments were proposed to measure it (for a review see Carmona, 2004b; Onwuegbuzie \& Wilson, 2000). From these, the STARS (Cruise, Cash, \& Bolton, 1985) was chosen because it is commonly used (e.g. Bell, 1998; D’Andrea \& Waters, 2002; Nasser, 2004; Onwuegbuzie, 2000, 2003), and reliability and validity analyses have been conducted on the English version of the scale (Baloglu, 2002; Cruise et al., 1985). The Italian version of the STARS was validated through confirmatory factor analysis, which attested to the six-factor structure of the scale, and good indices for both reliability and validity were obtained (Chiesi, Primi, \& Ciancaleoni, 2008; Chiorri, Chiesi, Piattino, Primi, \& Vannucci, 2009).

It is a 51-item (5-point Likert format) instrument organized in two parts. For the purposes of the present investigation, only the first part of the STARS was used (in particular, two scales were excluded because they overlapped with the Value and Cognitive Competence attitude dimensions measured by the SATS). The first part includes 23 items scored from "No anxiety" to "Very much anxiety," related to different aspects of statistics anxiety as measured by three subscales: Interpretation anxiety (11 items) is concerned with anxiety experienced when students are faced with making a decision about or interpreting statistical data (e.g., "Reading a journal article that includes statistical analyses," "Interpreting the meaning of probability value once I have found it"), Test and class anxiety (8 items) referred to the anxiety involved when taking a statistics class or test (e.g. "Walking into a classroom to take a statistics test," "Doing the homework for a statistics course"), Fear of asking for help (4 items) measured the anxiety experienced when asking a fellow student or a teacher for help in understanding specific 
contents (e.g. "I'm going to ask my statistics teacher for individual help with materials that I have difficulty with understanding"). The STARS responses were summed in order to obtain scores for each scale: Interpretation anxiety (range 11-55), Test and class anxiety (range 8-40), and Fear of asking for help (range 4-20).

In accordance with previous research (Harlow et al., 2002; Lalonde \& Gardner, 1993; Nasser, 2004; Sorge \& Schau, 2002), more indicators were taken into account to measure statistics achievement:

A. Midcourse Tasks Score. Throughout the course (organized into three units) students were requested to solve three tasks (at the end of each unit). For each task, students were given a data matrix (3-4 variables, 10-12 cases) and they had to compute descriptive indices, report data in a two-way table or draw graphs, and choose and apply appropriate statistical tests (identify the null and the alternative hypotheses, decide the level of significance, find the critical value, calculate the value of the test, and make a decision). Each task consisted of two problems - to be solved by paper-and-pencil procedure without the support of a statistics computer package - and two conceptual open-ended questions (e.g., defining the null hypothesis in hypothesis testing). All the items pertained to content covered in class. For each problem the score ranged from 0 to 3: $0=$ totally incorrect or not solved; 1 = partially solved (e.g., only the descriptive indices were computed); 2 = almost solved (e.g., the descriptive indices were correctly computed and the appropriate test was chosen but errors were made in finding the critical value or making a decision/drawing a conclusion; $3=$ completely solved. For each question the score ranged from 0 to 2: $0=$ totally incorrect or no answer; $1=$ partially answered (e.g., only the definition or the example was given); 2 = correctly answered. Two independent raters (assistant teachers) scored the tasks. For the most part (about $90 \%$ ) there was agreement in the scores. When the ratings differed, a third rater checked the scores in order to obtain agreement. The three task scores were aggregated in a single measure by obtaining a mean score (range 1-10).

B. Final Examination Grade. This was assigned through an examination form that was constructed by the course instructors. It consisted of a written task and an oral exam. The written task had the same characteristics as the tasks presented during the course (problems and open-ended questions), that is, the midcourse tasks represented a short form of the final examination. Scores - given following the same procedure described above - ranged from 0 -30. From 0 to 17 the score was considered insufficient. Starting from 18, students passed, and were admitted to the oral exam which concerned the course program. For instance, students were asked to describe the procedure to solve a problem, or they were asked about theoretical issues. The oral exam provided the students with an opportunity to improve their performance (from 0 to 3 points). The final grade - derived both from the written and verbal parts - was from 18 to 30 in accordance with the Italian University Grading System. The lecturer gave the grades together with an assistant teacher.

C. Failures. As documented in detail in previous research (Galli et al., 2008; Primi \& Chiesi, 2007), sometimes students were unsuccessful in the final examination (i.e., under 18 , the minimum passing grade) and some of them needed several attempts to pass. The number of failed attempts was taken into account when measuring the final performance (see below for the scoring procedure). After a failed attempt, students were given the possibility to revise the task with an assistant teacher in order to check the missed parts and the errors, and they received instruction about the required procedures. 


\subsection{PROCEDURE}

The pre-SATS was administered at the beginning of the course during the first day of class. The PMP was completed during the second day of class, the STARS was administered around the middle of the course and the post-SATS at the end of the classes. Each questionnaire was introduced briefly to the students and instructions for completion were given. Answers were collected in paper-and pencil format and the time needed to complete them ranged from 15 to 30 minutes.

For the three tasks students solved during the course they had one hour for each, and books and notes were not allowed to be used. After the sessions the solutions were presented and discussed with the students. Exam sessions started soon after the end of the course. The written exam was timed (2 hours) and was followed by the oral examination. Failed attempts were registered for students who did not pass the final examination.

\section{RESULTS}

Several stages of data preparation were completed before conducting the SEM analysis. Because approximately $70 \%$ of the students had no learning debts, and $30 \%$ of the students had one or more, the learning debts variable was transformed into a dichotomous variable (no debts vs. at least one debt). The failures distribution presented a strong departure from the normal distribution (about $67 \%$ of students never failed, and $22 \%$ failed at least once) and it could not be used directly as an indicator of the achievement inside the model. As failures had been demonstrated to be a significant feature of the introductory statistics exam (Galli et al., 2008; Primi \& Chiesi, 2007), in order to take it into account, final exam scores were computed considering the final examination score minus the number of failures (e.g., if a student obtained 23 points but they failed twice before passing the examination, their final score was 21). This way we obtained "weighted" scores based on the criterion that the same final score has a different weight if the score was obtained at the first attempt or after one or more attempts.

The starting model (Model A) included 6 latent variables and 16 manifest variables (Figure 1): Previous mathematical achievement (Mathematics Background) was the exogenous latent variable that influenced directly both the mathematical competence showed at the beginning of the course (Mathematics Knowledge) and the attitudes toward statistics at the beginning of the course (Pre-course Attitudes). Both of these exogenous latent variables were linked to anxiety experienced during the course before the final examination (Anxiety), and the attitudes at the end of the course (Post-course Attitudes). Mathematics Knowledge, Post-course Attitude, and Anxiety were supposed to influence directly students' performance (Achievement). Pre-course Attitudes and Post-course Attitudes were measured through the four scores obtained for each subscale of the SATS, and covariance paths were traced between errors of subscales measuring the same attitude dimension. Mathematics grades and learning debts were used as indicators for Mathematics Background and the PMP score for Mathematics Knowledge. The three scores of the STARS subscales were used as indicators of Anxiety. Achievement was measured through midcourse test grades and the adjusted final grade (taking into account the number of failues).

Univariate distributions of all variables included in the model (except the dichotomous one) were examined for identifying potential outliers and for assessment of normality. Scores that were outside of \pm 3.00 standard deviations from their mean were eliminated from analyses when they were clearly separated from other scores in the distribution to prevent undue influence of outliers on model evaluation (Bollen, 1989a). 


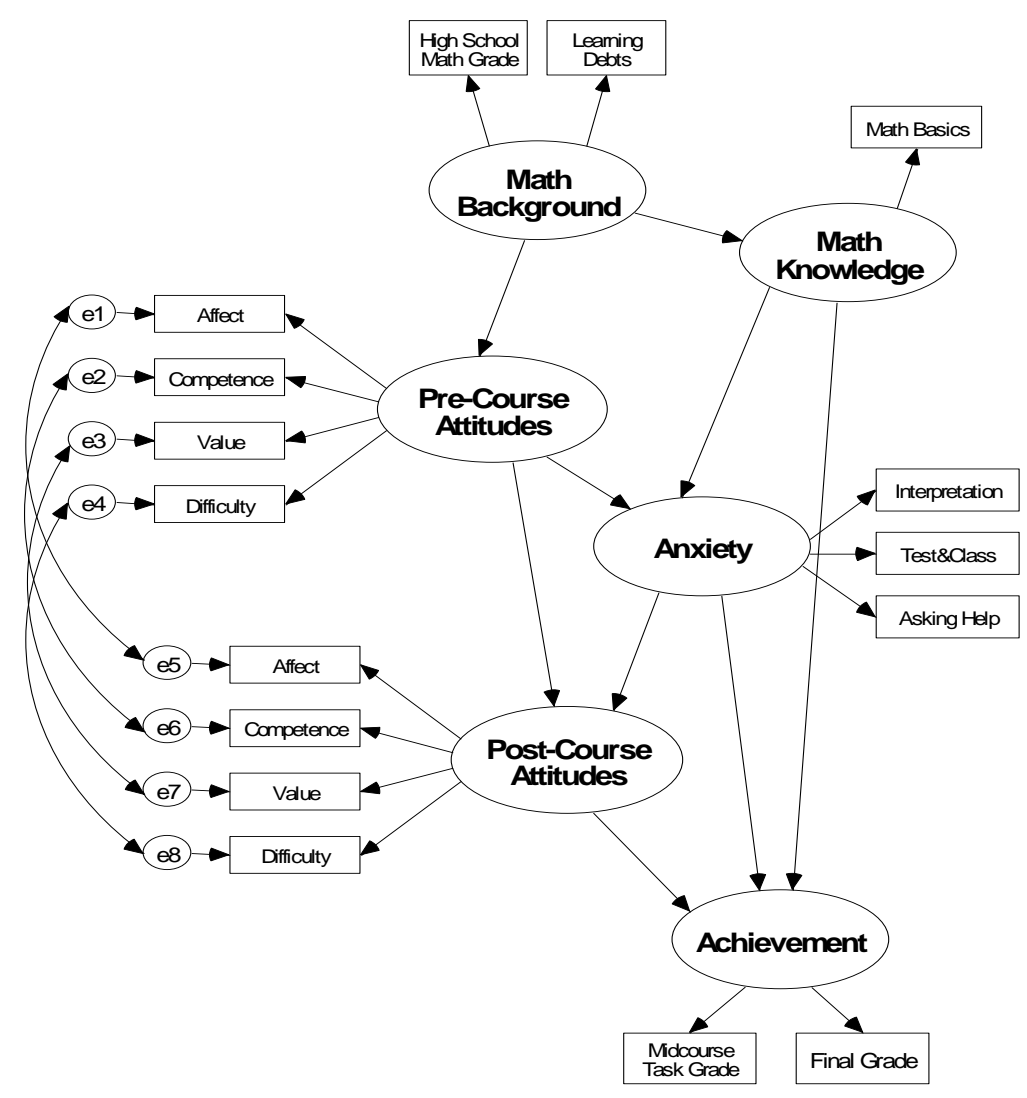

Figure 1. Initial Model of Statistics Achievement (Model A)

Error terms are not displayed except residual covariances among the four scales of the pre-SATS

(Pre-Course Attitudes) and the post-SATS (Post-Course Attitudes)

Few cases were eliminated following this procedure, and there were no outliers for Mathematics grades, Mathematics test, Midcourse test scores, and Final Grade. Skewness indices, ranging from -0.50 to 0.56 , attested that the departures cannot be expected to lead to appreciable distortions (Marcoulides \& Hershberger, 1997; Muthén \& Kaplan, 1985) with the exception of the PMP score distribution which was negatively skewed (Skewness $=-1.00)$. A log-transformation [ $\log _{10}(K-X)$, where $\left.K=X_{\max }+1\right]$ was applied to the PMP scores. After this transformation, scores were reversed in order to obtain high levels of mathematics ability corresponding to high ratings, and vice versa. Scores ranged from 0 to 1.4 .

Finally, starting from the assumption that missing values for the Final Grade variable - the outcome variable in the model - could not be replaced by a missing data treatment, a listwise deletion was conducted excluding cases without a final grade. For the remaining cases $(n=327)$, mean imputation was used, replacing missing data with the arithmetic mean of the variable. In order to avoid the excessive shrinking of variances by this procedure, for each variable involved, missing data were not allowed to exceed $10 \%$ of the total cases in the sample (Kline, 1998). 
Significant correlations were found between variables (see Appendix) which support the hypothesised relationships between latent constructs and the respective indicators, as well as between latent variables.

SEM analyses were conducted with AMOS 5.0 (Arbuckle, 2003) using maximum likelihood estimation on the variance-covariance matrix. Several fit indices were used to assess model data fit as suggested by Schumaker and Lomax (1996). Goodness-of-fit statistics reported are $\chi^{2} /$ degrees of freedom ratios (Marsh \& Hocevar, 1985; Wheaton, Muthén, Alwin, \& Summers, 1977), the root mean of square error of approximation (RMSEA) (Browne \& Cudeck, 1993; Steiger \& Lind, 1980) with the relative 90\% confidence interval, the comparative fit index (CFI) (Bentler, 1990), the Tucker-Lewis index (TLI) (Bentler \& Bonnet, 1980; Tucker \& Lewis, 1973), the normed fit index (NFI) (Bentler \& Bonnet, 1980), the relative fit index (RFI) (Bollen, 1986), and the incremental fit index (IFI) (Bollen, 1989b).

Model A showed a good fit to the data (Table 1). All measurement coefficients were statistically significant and in the expected directions, just as the hypothesized covariances between the pre- and post- measurement errors of the four dimensions of the SATS. All the estimated structural coefficients were statistically significant with the exception of the parameters between Anxiety and Achievement $(-.08, p=.456)$ and between Mathematics Knowledge and Anxiety (.17, $p=.081$ ). The former path was removed and the new model (Model B) was tested. The goodness-of-fit indices were similar to those of the previous model (Table 1) and all the measurement and structural coefficients were significant. The difference between the Chi square values of Model A and Model B $\left(\Delta \chi^{2}=0.52, d f=1\right)$ was not significant, therefore Model B (the more parsimonious) was chosen.

Table 1. Goodness-of-fit Indices for the Alternative Models

\begin{tabular}{|c|c|c|c|c|c|c|c|c|c|}
\hline Model & $\chi^{2}$ & $d f$ & $\chi^{2} / d f$ & CFI & $T L I$ & $N F I$ & $R F I$ & $I F I$ & $\begin{array}{c}\text { RMSEA } \\
\text { (C.I.) }\end{array}$ \\
\hline Model A & 158.25 & 91 & 1.74 & .96 & .95 & .91 & .88 & .96 & $\begin{array}{c}.048 \\
(.036, .060)\end{array}$ \\
\hline Model B & 158.77 & 92 & 1.73 & .96 & .95 & .91 & .88 & .96 & $\begin{array}{c}.047 \\
(.035, .059)\end{array}$ \\
\hline Model C & 148.19 & 91 & 1.63 & .97 & .95 & .92 & .89 & .97 & $\begin{array}{c}.044 \\
(.031, .056)\end{array}$ \\
\hline Model D & 150.01 & 92 & 1.63 & .97 & .95 & .92 & .89 & .97 & $\begin{array}{c}.044 \\
(.031, .056)\end{array}$ \\
\hline
\end{tabular}

Standardized residuals were not significant at the .01 level (i.e., values were inside \pm 2.58 ) with minor exceptions. In particular, standardized residuals among PMP score and pre-Affect and pre-Competence were significant at the .001 level (i.e., values exceeded \pm 3.33 ) suggesting that the relationships between these variables was underestimated by the model (residuals were negative as well as the respective sample covariances). Therefore a path between Mathematics Knowledge and Pre-Course Attitudes was added to Model B. The resulting model (Model C) showed a very good fit (Table 1). The modification resulted in a significant difference between Chi-Square values $\left(\Delta \chi^{2}=10.58\right.$, $d f=1, p=.002$ ), therefore Model $\mathrm{C}$ (the more complex model) was chosen. All 
parameter estimates were significant and in the expected direction, except for the direct path from Mathematics Background and Pre-Course Attitudes $(.12, p=.173)$. This path was removed and the resulting model (Model D) was tested. Goodness of fit indices were analogous to those for Model C, and all the measurement and structural coefficients were significant. Comparing Model C and Model D, the difference between Chi-Square values was not significant $\left(\Delta \chi^{2}=1.82, d f=1\right)$, therefore Model D was chosen.

As expected, Mathematics Background had a direct negative effect on Mathematics Knowledge. A very strong relationship was found between Achievement and Mathematics Knowledge which was also related to Pre-Course Attitudes and Anxiety, although more weakly. Furthermore, Pre-Course Attitudes affected Anxiety negatively and Post-Course Attitudes positively. Finally, Anxiety was directly and negatively related to Post-Course Attitudes that, in turn, had a direct positive effect on Achievement (Figure 2).

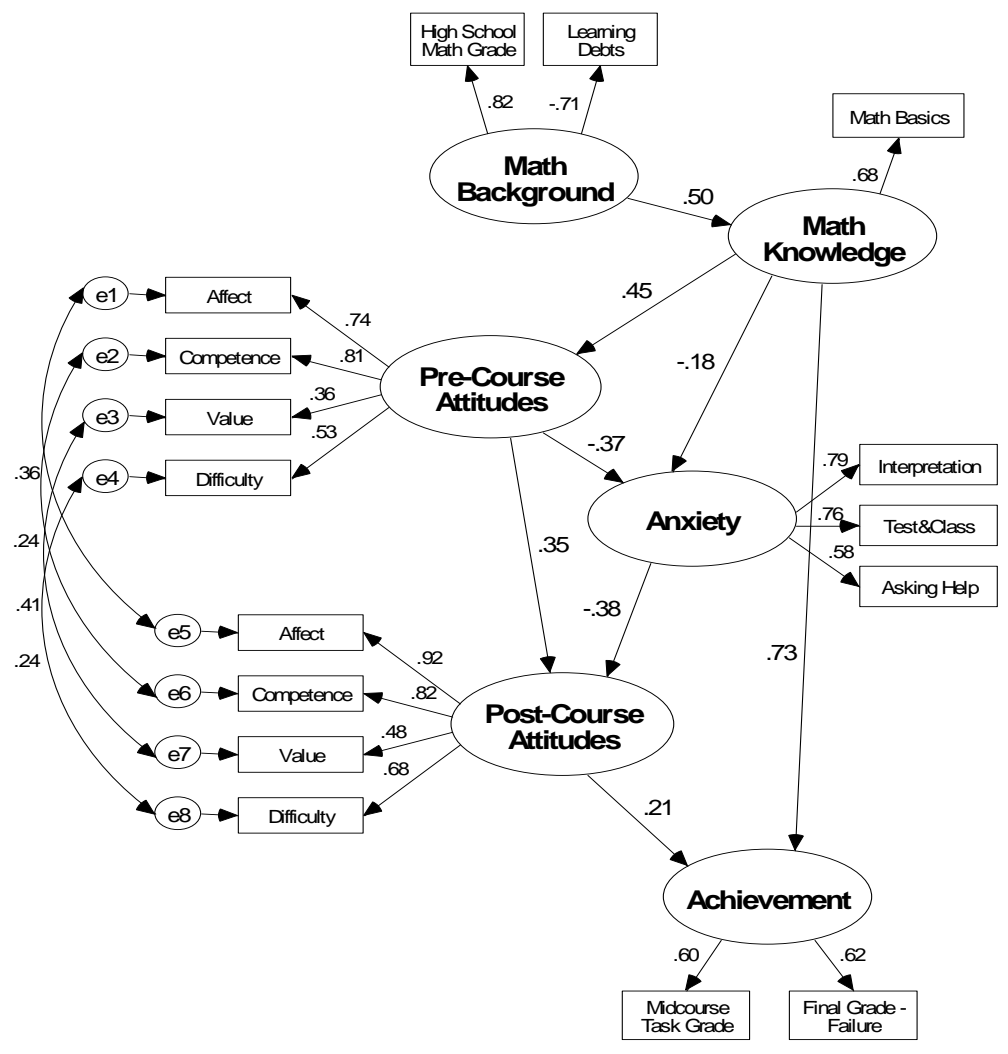

Figure 2. Final Model of Statistics Achievement (Model D) with standardized parameters (paths are all significant at the .05 level or lower)

Moreover, Mathematics Background had indirect effects on Pre-Course Attitudes (.23), Anxiety (-.18), Post-Course Attitudes (.15), and Achievement (.40). Mathematics Knowledge had an indirect effect on Post-Course Attitudes (.29) and Achievement (.08), and an indirect effect on Anxiety (-.17) through Pre-Course Attitudes. Pre-Course Attitudes had an indirect effect on Achievement (.11) through Post-Course Attitudes and an indirect effect on Post-Course Attitudes (.15) through Anxiety. Finally, Anxiety 
influenced Achievement indirectly (-.08) through Post-Course Attitudes. Table 2 displays all the effects derived from the direct and indirect paths of the final model.

Table 2. Standardized Direct and Indirect Effects in the Final Model (Model D)

\begin{tabular}{|c|c|c|c|c|c|c|}
\hline & & $\begin{array}{c}\text { Math } \\
\text { Knowledge }\end{array}$ & $\begin{array}{c}\text { Pre- } \\
\text { Course } \\
\text { Attitude }\end{array}$ & Anxiety & $\begin{array}{c}\text { Post- } \\
\text { cCourse } \\
\text { Attitude }\end{array}$ & Achievement \\
\hline \multirow{3}{*}{$\begin{array}{l}\text { Mathematics } \\
\text { Background }\end{array}$} & Direct & -.50 & I & 1 & I & 1 \\
\hline & Indirect & l & .23 & -.18 & .15 & .40 \\
\hline & Total & -.50 & .23 & -.18 & .15 & .40 \\
\hline \multirow{3}{*}{$\begin{array}{l}\text { Mathematics } \\
\text { Knowledge }\end{array}$} & Direct & & .45 & -.18 & I & .73 \\
\hline & Indirect & & / & -.17 & .29 & .07 \\
\hline & Total & & .45 & -.35 & .29 & .79 \\
\hline \multirow{3}{*}{$\begin{array}{l}\text { Pre-Course } \\
\text { Attitude }\end{array}$} & Direct & & & -.37 & .35 & 1 \\
\hline & Indirect & & & I & .15 & .11 \\
\hline & Total & & & -.37 & .50 & .11 \\
\hline \multirow{3}{*}{ Anxiety } & Direct & & & & -.38 & 1 \\
\hline & Indirect & & & & I & -.08 \\
\hline & Total & & & & -.38 & -.08 \\
\hline \multirow{3}{*}{$\begin{array}{l}\text { Post-Course } \\
\text { attitude }\end{array}$} & Direct & & & & & .21 \\
\hline & Indirect & & & & & / \\
\hline & Total & & & & & .21 \\
\hline
\end{tabular}

R-squared multiple correlations indicated that $67 \%$ of the variance in the latent outcome variable Achievement was accounted for by the latent independent variables. The model explains 39\% of the variance in the Post-Course Attitudes variable, 25\% of the variance in the Mathematics Knowledge variable, $24 \%$ in the Anxiety variable and, finally, 20\% in Pre-Course Attitudes.

In order to better ascertain the relationships between cognitive and non-cognitive factors, groups were created using the PMP score. Specifically, two groups were created using the median (23) of the PMP score as a cut-off: Students below the median were assigned to the low-knowledge group, and students at or over the median were assigned to the high-knowledge group. We ran a $2 \times 2$ mixed ANOVA with course (pre/post) as a within-subjects factor, and math knowledge (low/high) as between-subjects factors on attitudes toward statistics.

The ANOVA indicated a main effect of course $\left(F(1,181)=61.44, p<.001, \eta_{p}{ }^{2}=.25\right)$ which resulted in an overall improvement in attitude from the beginning $(M=116.25$, $S D=16.61)$ to the end $(M=125.63, S D=20.36)$ of the course. Moreover, there was a significant course by math knowledge interaction $\left(F(1,181)=4.60, p=.033, \eta_{p}{ }^{2}=.03\right)$. This indicated that attitude improved with the initial level of knowledge (Figure 3).

Investigating the differences related to the four attitude dimensions, the ANOVA indicated a main effect of course that resulted in an overall improvement in Affect ( $F(1$, 181)=15.22 $p<.001, \eta_{p}{ }^{2}=.08$; pre: $M=22.42, S D=5.56$, post: $M=24.15, S D=6.67$ ), Difficulty $\left(F(1,181)=26.39, p<.001, \eta_{p}{ }^{2}=.13\right.$; pre: $M=23.53, S D=4.11$, post: $M=25.52$, $S D=5.06)$, Cognitive Competence $\left(F(1,181)=126.84, p<.001 \quad \eta_{p}{ }^{2}=.41\right.$; pre: $M=26.17$, $S D=5.80$, post: $M=30.27, S D=6.14)$, and Value $\left(F(1,181)=8.09, p=.005 \eta_{p}{ }^{2}=.04\right.$; pre: $M=44.31, S D=7.38$, post: $M=45.78, S D=7.95)$. 


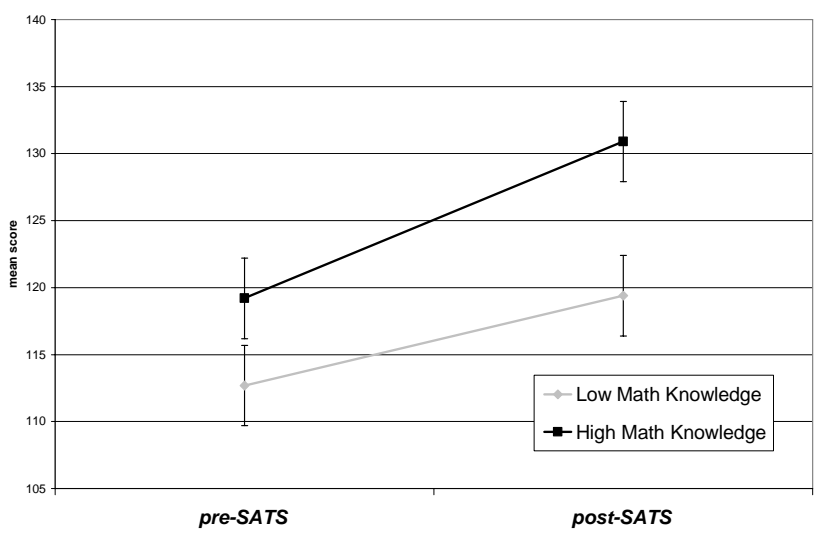

Figure 3. Attitude Toward Statistics (mean scores) at the beginning and at the end of the course in Low and High Mathematics Knowledge Groups

Significant course by math knowledge interactions in the case of both Affect ( $F(1$, $\left.181)=5.93, p=.106, \eta_{p}{ }^{2}=.03\right)$ and Difficulty $\left(F(1,181)=6.80, p=.009, \eta_{p}{ }^{2}=.04\right)$ were found, indicating that the magnitude of the increase in affect toward the discipline and perceived difficulty of the subject depended on the initial level of math competence. No significant course by math knowledge interactions were found for either Cognitive Competence $(F(1,181)=2.93$, n.s. $)$ or Value $(F(1,181)=0.06$, n.s. $)$, indicating that the increase in value attributed to the discipline and perceived cognitive competence were independent from the initial level of math competence (Figure 4).

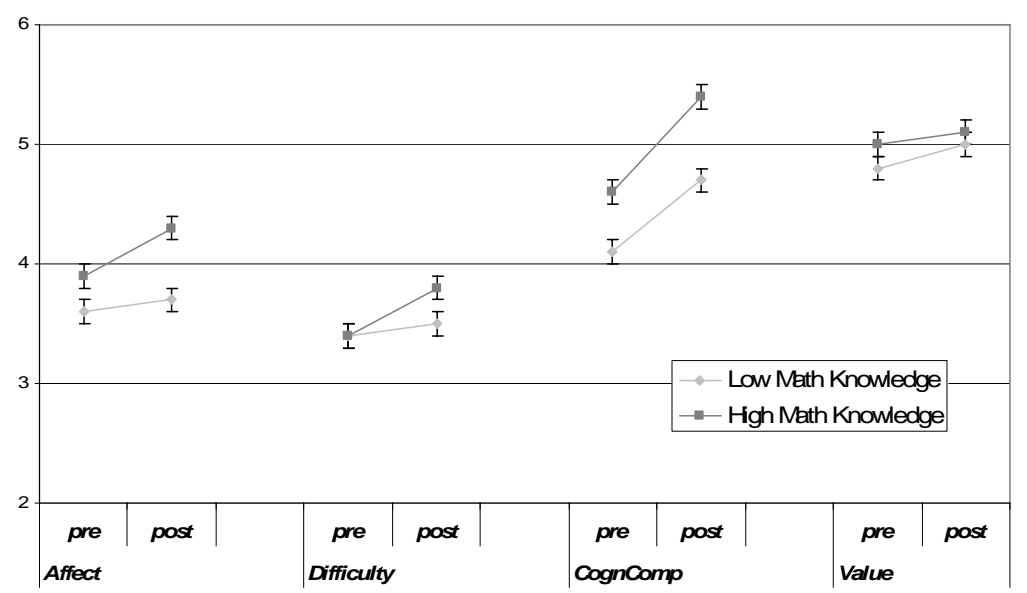

Figure 4. The Four Factors of Attitude towards Statistics (because each factor was composed of a different number of items, mean scores were obtained by dividing each factor score by the number of items) at the beginning and at the end of the course in Low and High Mathematics Knowledge Groups 


\section{DISCUSSION}

The purpose of the present research was to examine psychology students' achievement in an introductory statistics course in order to better ascertain the impact of both cognitive and non-cognitive factors on course performance. As expected, and in line with previous research (Harlow et al., 2002; Lalonde \& Gardner, 1993; Schutz et al., 1998; Tremblay et al., 2000), mathematical knowledge, acquired during high school, had a direct and strong effect on achievement. Additionally, attitudes toward the discipline affected achievement: Attitudes at the beginning of the course, directly related to mathematical knowledge, had an effect on attitudes at the end of the course that in turn influenced achievement (Sorge \& Schau, 2002; Wisenbaker et al., 2000). This indicates that the final value and difficulty as well as perceived competence and affect concurred in determining performance in statistics.

Concerning statistics anxiety, mathematics knowledge and pre-course attitudes were directly linked to anxiety that in turn affected post-course attitudes. Low competence and negative attitudes were accompanied by high levels of anxiety, and high levels of anxiety resulted in low final attitudes toward statistics, which yielded low performance. The hypothesized path between statistics anxiety and achievement was not observed, consistent with Lalonde and Gardner (1993) and Nasser (2004), but in contrast to Onwuegbuzie (2003) and Tremblay et al. (2000). The fact that anxiety appeared not to be related to performance might be explained considering that anxiety was measured in the middle of the course about two months before passing the examination. Moreover, because the present study analysed only linear relationships, possible non-linear relationships were missed, as suggested in a very recent study by Keeley, Zayac, and Correia (2008) in which it was reported that a curvilinear function between anxiety and achievement better explains this relationship (i.e., performance is poorer at both extremes of low and high levels of anxiety and it gradually improves as level of anxiety moves from these extremes).

The present results showed that attitudes toward statistics changed during the course, and that the magnitude of this impact depended on background characteristics (i.e., noncognitive factors might change depending on both experiences related to the course and on individual differences). Students come to a statistics course with great variation in expectations and perceptions regarding statistics partially related to their previous experiences with mathematics. At the beginning of the course those who had lower levels of mathematics competence were less self-confident, experienced more negative feelings, considered statistics worthier and harder than those with a high competence. At the end of the course, both groups' attitudes improved. Specifically, low-competence students did not change their feelings toward the discipline and their perception of the difficulty of the discipline, but their self-confidence increased and they attributed a higher value to statistics. High-competence students increased in all four attitude dimensions.

Concerning the course, we might suppose that experiencing the practice of statistics during the classes, students might became aware of its utility (e.g., during each class the theoretical issues were introduced using examples derived from the psychological research domain, so that this might have helped them to appreciate why statistics is worthy of learning and a useful tool for their professional training). Moreover, during the course students were usually asked to solve exercises - and encouraged to work in small groups in order to help each other - the answers to which were presented and discussed during the classes in order to give students feedback, enabling them to monitor their progress. This way they gradually realised that they could master the topics, they increased their self-confidence, and they came to perceive the subject as easier than at the 
start of the course. All of these factors also contributed to the reduction of negative feelings toward the discipline. In any case, it seems that students' individual levels of mathematical competence mediated the effects of the course (i.e., unlike high-knowledge students, low-knowledge students did not experience more positive feelings toward statistics and they did not change the idea that it is a complex and difficult subject).

Some pedagogical issues can be derived from this finding suggesting that mathematical competence and attitude toward statistics should be the focus of planning interventions to help students in increasing performance. Given that cognitive and noncognitive factors appear to be interrelated, and that both concur to determine achievement, intervention strategies should be aimed at increasing both basic mathematics knowledge and attitudes toward the discipline. This is especially important because students should be supported in changing not only their competence but also their perceived competence, the perceived difficulty and utility of the subject, as well as their feelings towards it.

For this purpose it might be useful to arrange a short series of lessons aimed at mastering the basic mathematical skills (rounding, factorials, order of operations in computations, basic algebra, and so on) required during the course. Indeed, in courses in which students are requested to solve problems without the support of statistics computer packages, it is important that they are familiar with some basic mathematical techniques that are necessary to solve the tasks. It does not mean that the assessment of statistics achievement depends solely on these basic mathematical techniques, but they constitute a necessary tool to keep in touch with statistics. Indeed, at least at the introductory level, we consider that it might be useful to learn to apply basic computational procedures - for example, to compute the standard deviation - in order to better understand the foundations of some basic statistical concepts - for example, that the standard deviation represents a measure of how spread out data are and is obtained by subtracting the mean from each value, and computing the mean of these deviations.

Moreover, to help students enhance their confidence in learning statistics it might be useful to give exercises that allow students to experience mastery of the topics, and to provide feedback about their results in order to allow them to monitor their progress. These exercises can help students, especially if they are embedded in cooperative activities in which they can interact within groups while performing specific tasks. In the same way, it might be relevant to promote the importance of the discipline, showing students that statistics is not an isolated subject inside their degree programs - for example, through explaining the importance of statistics for research in different domains, and to clarify statistical terminology and concepts using examples taken from current studies. Once problems with basic mathematics are reduced, all students should benefit from these intervention strategies.

Future research should aim to test the effectiveness of these pedagogical techniques: The impact of interventions directed in enhancing basic mathematical skills should be specifically assessed as well as the related effects on attitudes and performance. Collecting repeated measures of both cognitive and non-cognitive factors during the course might help in monitoring these changes and enhancements.

The present pedagogical suggestions concerning mathematical competence are, on the one hand, partially in contrast with standard educational documents proposed by the statistics education community (e.g., the GAISE document, Franklin et al., 2007), including the need for a lessened dependence on basic math ability. On the other hand, we posit that once competence and perceived competence are enhanced, conditions allowing for more authentic learning are provided (e.g., understanding measurement and 
sampling variability, grasping probability, perceiving the value of statistics in personal choices and careers), as the mentioned guidelines for teaching statistics recommend.

Finally, the student population from which we recruited our participants consisted of students who regularly attended the course and passed the final examination. In this way a sample of only two-thirds of the original group was involved in the analysis, and the missing data were non-random. This is a limitation of the study that we have to take into account when interpreting the findings. However, there is no easy way to solve this problem, if we want to study students' achievement. Future investigations should also be aimed at looking at the cognitive and non-cognitive characteristics of students who attend the course but do not pass the exam, and also at exploring whether the planned intervention strategies might help in reducing their number.

\section{REFERENCES}

Arbuckle, J. L. (2003). Amos 5.0 [Computer software]. Chicago: Smallwaters.

Auzmendi, E. (1991, April). Factors related to attitude toward statistics: A study with a Spanish sample. Paper presented at the annual meeting of the American Educational Research Association, Chicago, IL.

Baloglu, M. (2002). Psychometric properties of the statistics anxiety scale. Psychological Reports, 90(11), 315-125.

Bandalos, D. L., Finney, S. J., \& Geske, J. A. (2003). A model of statistics performance based on achievement goal theory. Journal of Educational Psychology, 95(3), 604616.

Bell, J. A. (1998). International students have statistics anxiety too! Education, 118(4), 634-636.

Bentler, P. M. (1990). Comparative fit indexes in structural models. Psychological Bulletin, 107(2), 238-246.

Bentler, P. M. (1995). EQS: Structural equations program manual. Encino, CA: Multivariate Software, Inc.

Bentler, P. M., \& Bonett, D. G. (1980). Significance tests and goodness of fit in the analysis of covariance structures. Psychological Bulletin, 88(3), 588-606.

Bollen, K. A. (1986). Sample size and Bentler and Bonett's nonnormed fit index. Psychometrika, 51(3), 375-377.

Bollen, K. A. (1989a). Structural equations with latent variables. New York: Wiley.

Bollen, K. A. (1989b). A new incremental fit index for general structural equation models. Sociological Methods and Research, 17(3), 303-316.

Browne, M. W., \& Cudeck, R. (1993). Alternative ways of assessing model fit. In K. A. Bollen, \& J. S. Long (Eds.) Testing structural equation models (pp. 136-162). Newbury Park, CA: Sage.

Budé, L., Van De Wiel, M. W. J., Imbos, T., Candel, M. J. J. M., Broers, N. J., \& Berger, M. P. F. (2007). Students' achievements in a statistics course in relation to motivational aspects and study behaviour. Statistics Education Research Journal, 6(1), 5-21.

[Online: http://www.stat.auckland.ac.nz/ iase/serj/SERJ6(1)_Bude.pdf]

Carmona, M. J. (2004a, July). Mathematical background and attitudes toward statistics in a sample of undergraduate students. Paper presented at the $10^{\text {th }}$ International Congress on Mathematics Education, Copenhagen, Denmark.

[Online: http://www.stat.auckland.ac.nz/ iase/publications/11/Carmona.doc]

Carmona, M. J. (2004b). Una revisión de las evidencias de fiabilidad y validez de los cuestionarios de actitudes y ansiedad hacia la estadística [A review of the evidence of 
reliability and validity of questionnaires of attitudes and anxiety towards statistics]. Statistics Education Research Journal, 3(1), 5-28.

Carmona J., Primi, C., \& Chiesi, F. (2008, July). Testing for measurement invariance of the Survey of Attitudes Toward Statistics: A comparison of Italian and Spanish students. III European Congress of Methodology, Oviedo, Spain.

Cashin, S. E., \& Elmore, P. B. (2005). The Survey of Attitudes Toward Statistics scale: A construct validity study. Educational and Psychological Measurement, 65(3), 1-16.

Chiesi, F,. \& Primi, C. (2009). Assessing statistics attitudes among college students: Psychometric properties of the Italian version of the Survey of Attitudes Toward Statistics (SATS). Learning and Individual Differences, 19(2), 309-313.

Chiesi, F., Primi, C., \& Ciancaleoni, M. (2008). Le proprietà psicometriche della Statistics Anxiety Rating Scale [The psychometric properties of STARS ]. Psicologia dell'Educazione, 3(2), 48-58.

Chiorri C., Chiesi F., Piattino S., Primi C., \& Vannucci M. (2009). Ansia nei confronti della statistica e stile cognitivo: Un'indagine sugli studenti di psicologia [Anxiety about statistics and cognitive style: A survey of psychology students]. Proceedings of the III Congress "Verso una nuova qualità dell'insegnamento e apprendimento della Psicologia." [Online: http://convdidattica.psy.unipd.it/]

Ciancaleoni, M., Galli, S., Chiesi, F., \& Primi, C. (2008, July). Assessing the predictive validity of the mathematical ability scale constructed applying the Rasch model. Paper presented at III European Congress of Methodology, Spagna, Oviedo.

Cruise, J. R., Cash, R. W., \& Bolton, L. D. (1985). Development and validation of an instrument to measure statistical anxiety. In American Statistical Association Proceedings of the Section on Statistical Education (pp. 92-97). Alexandria, VA: American Statistical Association.

D’Andrea, L., \& Waters, C. (2002). Teaching statistics using short stories: Reducing anxiety and changing attitudes. In B. Phillips (Ed.), Proceedings of the Sixth International Conference on Teaching Statistics: Developing a statistically literate society, Cape Town, South Africa. [CD-ROM]. Voorburg, The Netherlands: International Statistical Institute.

[Online: http://www.stat.auckland.ac.nz/ iase/publications/1/8a2_dand.pdf ]

Dauphinee, T. L., Schau, C., \& Stevens, J. J. (1997). Survey of Attitudes Toward Statistics: Factor structure and factorial invariance for female and males. Structural Equation Modeling, 4(2), 129-141.

Eccles, J., Adler, T. F., Futterman, R., Goff, S. B., Kaczala, C. M., Meece, J. L., et al. (1983). Expectations, values, and academic behaviors. In J. T. Spence (Ed.), Achievement and Achievement Motivation (pp. 75-146). W. H. Freeman: San Francisco.

Elmore, P. B., \& Lewis, E. L. (1991, April). Statistics and computer attitudes and achievement of students enrolled in Applied Statistics: Effect of a computer laboratory. Paper presented at the Annual Meeting of the American Educational Research Association, Chicago, IL.

Feldt, L. B., Woodruff, D. J., Salih, F. A., \& Srichai, M. (1986). Statistical tests and confidence intervals for Cronbach's coefficient alpha (Iowa Testing Programs Occasional Papers No. 33). (ERIC Document Reproduction Service No. ED291755)

Finney, S. J., \& Schraw, G. (2003). Self-efficacy beliefs in college statistics courses. Contemporary Educational Psychology, 28(2), 161-186.

Fitzgerald, S. M., Jurs, S., \& Hudson, L. M. (1996). A model predicting statistics achievement among graduate students. College Student Journal, 30, 361-366. 
Franklin, C. A., Kader, G., Mewborn, D., Moreno, J., Peck, R., Perry, M., et al. (2007). Guidelines for assessment and instruction in statistics education (GAISE) report: A pre-K-12 curriculum framework. Alexandria, VA: American Statistical Association. [Online: http://www.amstat.org/Education/gaise/GAISECollege.htm]

Gal, I., Ginsburg, L., \& Schau, C. (1997). Monitoring attitudes and beliefs in statistics education. In I. Gal \& J. B. Garfield (Eds.), The assessment challenge in statistics education (pp. 37-51). Amsterdam: IOS Press.

Galli, S., Chiesi, F., \& Primi, C. (2008). The construction of a scale to measure mathematical ability in psychology students: An application of the Rasch Model. TPM (Testing Psicometria Metodologia), 15(1), 1-16.

Garfield, J. (2003). Assessing statistical reasoning. Statistics Education Research Journal, 2(1), 22-38.

[Online: http://www.stat.auckland.ac.nz/ iase/serj/SERJ2(1).pdf]

Gravetter, F. J., \& Wallnau, L. B. (1996). Statistics for the behavioural sciences: A first course for students of psychology and education. St. Paul, MN: West.

Harlow, L. L., Burkholder, G. J., \& Morrow, J. A. (2002). Evaluating attitudes, skill, and performance in a learning-enhanced quantitative methods course: A structural modelling approach. Structural Equation Modeling, 9(3), 413-430.

Hilton, S. C., Schau, C., \& Olsen, J. A. (2004). Survey Attitudes Toward Statistics: Factor structure invariance by gender and by administration time. Structural Equation Modeling, 11(1), 92-109.

Keeley, J., Zayac, R. M., \& Correia, C. (2008). Curvilinear relationships between statistics anxiety and performance among undergraduate students: Evidence for optimal anxiety. Statistics Education Research Journal, 7(1), 4-15.

[Online: http://www.stat.auckland.ac.nz/ iase/serj/SERJ7(1)]

Kline, R. B. (1998). Principles and practice of Structural Equation Modeling. New York: Guilford Press.

Lalonde, R. N., \& Gardner, R. C. (1993). Statistics as a second language? A model for predicting performance in psychology students. Canadian Journal of Behavioural Science, 25(1), 108-125.

Marcoulides, G. A., \& Hershberger, S. L. (1997). Multivariate statistical methods. A first course. Mahwah, NJ: Lawrence Erlbaum Associates.

Marsh, H. W., \& Hocevar, D. (1985). Application of confirmatory factor analysis to the study of self-concept: First- and higher-order factor models and their invariance across groups. Psychological Bulletin, 97(3), 562-582.

McCall, C. H., Belli, G., \& Madjidi, F. (1991). The complexities of teaching graduate students in educational administration introductory statistical concepts. PICTeachSt, 3, 495-497.

Muthén, B., \& Kaplan, D. (1985). A comparison of some methodologies for the factor analysis of non-normal Likert variables. British Journal of Mathematical and Statistical Psychology, 38(1), 171-189.

Nasser, F. (2004). Structural model of the effects of cognitive and affective factors on the achievement of Arabic-speaking pre-service teachers in introductory statistics. Journal of Statistics Education, 12(1).

[Online: www.amstat.org/publications/ jse/v12n1/nasser.html]

Onwuegbuzie, A. J. (1998). Statistics anxiety: A function of learning style? Research in School, 5(1), 43-52.

Onwuegbuzie, A. J. (2000). Statistics anxiety and the role of self-perceptions. Journal of Educational Research, 93(5), 323-335. 
Onwuegbuzie, A. J. (2003). Modeling statistics achievement among graduate students. Educational and Psychological Measurement, 63(6), 1020-1038.

Onwuegbuzie, A. J., \& Seaman, M. (1995). The effect of time constraints and statistics test anxiety on test performance in a statistics course. Journal of Experimental Education, 63(2), 115-124.

Onwuegbuzie, A. J., \& Wilson, V. A. (2000, November). Statistics anxiety: Nature, etiology, antecedents, effects, and treatments: A comprensive review of the literature. Paper presented at the Annual Meeting of the Mid-South Educational Research Association, Lexington, KY.

Onwuegbuzie, J. A., Bailey, P., \& Daley, C. E. (2002). The role of foreign language anxiety and students' expectations in foreign language learning. Research in the Schools, 9(1), 33-50.

Perney, J., \& Ravid, R. (1990, April). The relationship between attitudes toward statistics, math self-concepts, test anxiety and graduate students' achievement in an introductory statistics course. Paper presented at the Annual Meeting of the American Educational Research Association, Boston.

Primi, C., \& Chiesi, F. (2007). Come promuovere il rendimento all'esame di Psicometria: un modello per identificare i predittori sui quali intervenire [How to promote the efficiency of psychometrics under consideration: A model to identify the influential predictors]. Proceedings of the $I^{\circ}$ Convegno "Verso una nuova qualità dell'insegnamento e apprendimento della Psicologia” (pp. 624-637).

[Online: http://convdidattica.psy.unipd.it/]

Roberts, D. M., \& Bilderback, E. W. (1980). Reliability and validity of statistics attitudes survey. Educational and Psychological Measurement, 40(1), 235-238.

Schau, C. (2003, August). Students' attitudes: The "other" important outcome in statistics education. Paper presented at the Joint Statistical Meetings, San Francisco, CA.

Schau, C., Stevens, J. J., Dauphinee, T. L., \& Del Vecchio, A. (1995). The development and validation of the survey of attitudes toward statistics. Educational and Psychological Measurement, 55(5), 868-875.

Schumaker, R. E., \& Lomax, R. G. (1996). A beginner's guide to structural equation modeling. Mahwah, NJ: Lawrence Erlbaum.

Schutz, P. A., Drogosz, L. M., White, V. E., \& Distefano, C. (1998). Prior knowledge, attitude, and strategy use in an introduction to statistics course. Learning and Individual Differences, 10(4), 291-308.

Sorge, C., \& Schau, C. (2002, April). Impact of engineering students' attitudes on achievement in statistics: A structural model. Paper presented at the Annual Meeting of the American Educational Research Association, New Orleans.

Steiger, J. H., \& Lind, J. C. (1980, May). Statistically-based tests for the number of common factors. Paper presented at the Annual Spring Meeting of the Psychometric Society, Iowa City.

Tempelaar, D. T., van Der Loeff, S. S., \& Gijselaers, W. H. (2007). A structural equation model analyzing the relationship of students' attitudes toward statistics, prior reasoning abilities and course performance. Statistics Education Journal, 6(2), 78102.

[Online: http://www.stat.auckland.ac.nz/ iase/serj/SERJ6(2)_Tempelaar.pdf]

Tremblay, P.F., Gardner, R. C., \& Heipel, G. (2000). A model of the relationships among measures of affect, aptitude, and performance in introductory statistics. Canadian Journal of Behavioral Science, 32(1), 40-48. 
Tucker, L. R., \& Lewis, C. (1973). A reliability coefficient for maximum likelihood factor analysis. Psychometrika, 38(1), 1-10.

Wheaton, B., Muthén, B., Alwin, D. F., \& Summers, G. F. (1977). Assessing reliability and stability in panel models. In D. R. Heise (Ed.), Sociological methodology (pp. 84136). San Francisco, CA: Jossey-Bass.

Wise, S. L. (1985). The development and validation of a scale measuring attitudes toward statistics. Educational and Psychological Measurement, 45(2), 401-405.

Wisenbaker, J. M., Scott, J. S., \& Nasser, F. (2000, July/August). Structural equation models relating attitudes about and achievement in introductory statistics courses: A comparison of results from the U.S. and Israel. Paper presented at the $9^{\text {th }}$ International Congress on Mathematics Education, Tokyo, Japan.

Zeidner, M. (1991). Statistics and mathematics anxiety in social science students: Some interesting parallels. British Journal of Educational Psychology, 61(3), 319-328.

FRANCESCA CHIESI

Department of Psychology, University of Florence via di San Salvi 12, Complesso di San Salvi, Padiglione 26

50135 Florence ITALY 


\section{APPENDIX}

Means, Standard Deviations, and Correlations Among All Observed Variables Selected for the Structural Equation Model

\begin{tabular}{|c|c|c|c|c|c|c|c|c|c|c|c|c|c|c|c|c|c|}
\hline & $M$ & $s d$ & 1. & 2. & 3. & 4. & 5. & 6. & 7. & 8. & 9. & 10. & 11. & 12. & 13. & 14. & 15. \\
\hline 1. HS Math Grade & 6.67 & 1.16 & & & & & & & & & & & & & & & \\
\hline 2. HS Learning Debts & 0.25 & 0.43 & $-.59^{* *}$ & & & & & & & & & & & & & & \\
\hline 3. Pre-Affect & 22.34 & 4.74 & $.22^{* *}$ & $-.13^{*}$ & & & & & & & & & & & & & \\
\hline 4. Pre-Competence & 26.19 & 5.24 & $.19^{* *}$ & $-.14^{*}$ & $.59^{* *}$ & & & & & & & & & & & & \\
\hline 5. Pre-Value & 44.63 & 6.66 & $.19^{* *}$ & $-.12^{*}$ & $.28^{* *}$ & $.29^{* *}$ & & & & & & & & & & & \\
\hline 6. Pre-Difficulty & 23.16 & 3.97 & .10 & $-.12^{*}$ & $.43^{* *}$ & $.43^{* *}$ & $.14^{*}$ & & & & & & & & & & \\
\hline 7. Math Test $(\mathrm{Log})$ & 0.83 & .31 & $.23^{* *}$ & $-.21^{* *}$ & $.28^{* *}$ & $.30^{* *}$ & $.13^{*}$ & .06 & & & & & & & & & \\
\hline 8. Interpretation Anxiety & 23.87 & 6.37 & -.06 & -.03 & $-.24^{* *}$ & $-.29^{* *}$ & $-.12^{*}$ & $-.11^{*}$ & $-.20^{* *}$ & & & & & & & & \\
\hline 9. Test\&Class Anxiety & 26.08 & 4.42 & -.08 & .07 & $-.31^{* *}$ & $-.35^{* *}$ & -.07 & $-.17^{* *}$ & $-.14^{* *}$ & $.59^{* *}$ & & & & & & & \\
\hline 10. Asking Help & 8.77 & 2.56 & -.06 & .01 & $-.20^{* *}$ & $-.21^{* *}$ & -.01 & -.03 & $-.13^{*}$ & $.47^{* *}$ & $.45^{* *}$ & & & & & & \\
\hline 11. Post-Affect & 23.95 & 5.19 & $.13^{*}$ & -.06 & $.43^{* *}$ & $.43^{* *}$ & $.17^{* *}$ & $.22^{* *}$ & $.32^{* *}$ & $-.38^{* *}$ & $-.39^{* *}$ & $-.22^{* *}$ & & & & & \\
\hline 12. Post-Competence & 30.20 & 4.59 & $.14^{*}$ & $-.12^{*}$ & $.31^{* *}$ & $.47^{* *}$ & $.12^{*}$ & $.22^{* *}$ & $.34^{* *}$ & $-.42^{* *}$ & $-.38^{* *}$ & $-.23^{* *}$ & $.75^{* *}$ & & & & \\
\hline 13. Post-Value & 45.81 & 6.40 & $.14^{*}$ & -.05 & $.13^{*}$ & $.21^{* *}$ & $.41^{* *}$ & .07 & .10 & $-.20^{* *}$ & -.08 & -.09 & $.44^{* *}$ & $.41^{* *}$ & & & \\
\hline 14. Post-Difficulty & 25.13 & 4.03 & .02 & .02 & $.22^{* *}$ & $.26^{* *}$ & .06 & $.29^{* *}$ & $.17^{* *}$ & $-.29^{* *}$ & $-.29^{* *}$ & $-.15^{* *}$ & $.64^{* *}$ & $.54^{* *}$ & $.23^{* *}$ & & \\
\hline 15. Midcourse Tasks & 6.38 & 1.46 & $.17^{* *}$ & $-.16^{* *}$ & .03 & $.16^{* *}$ & .09 & -.06 & $.39^{* *}$ & $-.21^{* *}$ & $-.13^{*}$ & $-.11^{*}$ & $.25^{* *}$ & $.27^{* *}$ & $.11^{*}$ & $.14^{* *}$ & \\
\hline 16. Final Grade & 22.86 & 4.62 & $.29^{* *}$ & $-.27^{* *}$ & $.15^{* *}$ & $.19^{* *}$ & .09 & .07 & $.31^{* *}$ & $-.25^{* *}$ & $-.18^{* *}$ & $-.15^{* *}$ & $.27^{* *}$ & $.26^{* *}$ & $.19^{* *}$ & $20^{* *}$ & $.37^{* *}$ \\
\hline
\end{tabular}

** Correlation is significant at the 0.01 level (2-tailed)

* Correlation is significant at the 0.05 level (2-tailed) 